\title{
Influence of Contact Surface Type on the Mechanical Damages of Apples Under Impact Loads
}

\author{
Piotr Komarnicki $^{1} \cdot$ Roman Stopa $^{1} \cdot$ Daniel Szyjewicz $^{1} \cdot$ Lukasz Kuta $^{1}$ • \\ Tomasz Klimza ${ }^{1}$
}

Received: 25 October 2016 / Accepted: 5 April 2017 / Published online: 26 April 2017

(C) The Author(s) 2017. This article is an open access publication

\begin{abstract}
This paper presents an analysis of mechanical damage carried out on 'Golden Delicious' apple variety, which was subjected to impact loads during free drop against various rigid plates. For this purpose, an analysis of the contact pressure based on determined contours and surface pressure distributions at the contact point between the fruit dropped from various heights against fixed hard plates was performed. The impact test was conducted by means of Tekscan ${ }^{\circledR}$ system supported by computer verifying analysis. To obtain impact loads as well as their courses, the surface pressures and the bruise volumes were determined. Furthermore, use of ultrathin pressure sensors allowed for determination of the characteristic shape of contact area and the impact of fruit onto rigid plate. The results showed that the impact of fruit against rigid surface (concrete, wood) generates high values of maximum surface pressure and the bruise volume, observed at dropping from $10 \mathrm{~mm}$. A decrease in hardness of the test material (polyethylene foam) with decreasing maximum surface pressure approximately twice was noticed. The polyethylene foam is one of the best materials which protect fruit from mechanical damage, confirmed by the relation of bruise surface to contact surface, which did not exceed $35 \%$ during the impact at $150 \mathrm{~mm}$. The results of proposed studies can contribute to developing of harvest, handling, and transport processes, aiming at reduction in losses among fruit growers and production costs, i.e., by improvement of transport method.
\end{abstract}

Piotr Komarnicki

piotr.komarnicki@up.wroc.pl

1 Institute of Agricultural Engineering, The Faculty of Life Sciences and Technology, Wrocław University of Environmental and Life Sciences, Wrocław, Poland
Keywords Surface pressure $\cdot$ Impact $\cdot$ Contact plane $\cdot$ Bruise volume $\cdot$ Substrate $\cdot$ Apple

\section{Introduction}

In the last decade, as a result of economic globalization, the consumers require health as well as high quality providing food an esthetic appearance. To fulfill these expectations, food technologists, as well as geneticists and machine builders, should have an access to accurate data describing mechanical properties of agricultural products. These data should encompass not only the plant tissue but also the whole aspect of the agricultural products. In addition, the apples are characterized by high water content.

During harvest, transport, handling, sorting, and packaging, fruits are subjected to various static, dynamic, or impact loads. These effects cause visible bruises which lead to decrease in fruit quality. The bruise size depends mainly on mechanical properties of apple flesh. Moreover, bruise is classified as the most crucial cause influencing fresh fruit deterioration (Ahmadi et al. 2016; Li et al. 2016; Nicolaï et al. 2007; Opara 2007; Opara and Pathare 2014; Pang et al. 1992; UchechukwuAgua et al. 2015). Especially, during transport and handling, apples are stacked, i.e., in wooden boxes or other containers. In many cases, they are not protected against vibrations. The size of fruit damage resulting from transport process depends on various factors: susceptibility to damage, transport method, and type of container to which fruit ends up (Delele et al. 2013; Fadiji et al. 2016a, b; Holt and Schrool 1984; Rohm et al. 1997). Mostly, these products are placed in layers in different-sized containers. Measurement conducted by Timm et al. (1996) confirmed that transport of apples placed in bulk in plastic containers generates lower bruise area resulting from contact of fruit against the container's wall in comparison to a 
wall made from hardwood. Acican et al. (2007) studied mechanical forces affecting apples during transport in a wooden box and confirmed that on the bottom layer impacting force values were higher than those on the top layer. The large number of layers results in higher pressure values acting on the material (Caleb et al. 2011; Pathare et al. 2012). It can be concluded that the highest pressure values occur in the lowest part of the container. Usually, fruit places on the bottom layer in the transported box used to deform and have clearly visible damages in the form of dark-colored prints, which resulted from deformation in the flesh cells (Holt and Schrool 1977; Jones et al. 1991; Pathare et al. 2013; Rodriguez et al. 1990; Schulte et al. 1991; Wu and Pitts 1999). Bruises take color accurate to the force value (Cubero et al. 2011; Menesatti et al. 2009). Therefore, a non-destructive method to detect damages which is based on a thermovision camera was used (Kheiralipour et al. 2013). Research conducted by Doosti-Irani et al. (2016) follows that the thermal imaging system allows to determine the relationship between inside and outside temperatures of destructed tissue.

The bruise size resulting from impact load differs significantly from changes triggered by quasi-static load. During impact load, irreversible destructions in the external as well as in the internal structure occur rapidly, focusing mostly on mechanical deformation of fruit peel as well as permanent spatial deformation in parenchyma cells ( $\mathrm{Li}$ and Colin 2014). Based on these circumstances, an analysis of mechanical bruise occurrence and determination of bruise threshold has been analyzed using only the compression test.

Therefore, these experiments have been commonly conducted including measurements of impact load by means of a pendulum test on fruit, which dropped from various heights and hit onto a hard surface (Blahovec and Paprštein 2005; Elmasry et al. 2012; Komarnicki et al. 2016; Opara 2007). These tests have been used, i.e., to determine the bruise susceptibility in apple. Key parameters in assessing this phenomenon include impact level necessary to calculate the impact energy and volume of deformed tissue. This measurement of bruise volume is considered as an independent way if the bruised surface resembles a circular or elliptical shape (Costa et al. 2011). In the literature, the following methods to measure bruise volume were up till now used: bruise thickness method (Mohsenin 1986), full-depth method (Saltveit 1984), enclosed volume (Holt and Schrool 1977), unbruised volume removed (Pang et al. 1992), and ellipsoid (Hung and Prussia 1989). It can be concluded that to complete lacks in knowledge and to explain the process of bruise occurrence, an analysis of surface pressure in comparison to the results obtained through a damage volume measurement can be conducted.

In practice, to determine surface pressure, scientists used to apply the Hertz formulas, although they were derived based on assumptions excluding their application to biological objects. Rabelo et al. (2001) applied the Hertz method to analyze the contact surface in oranges, but the results clearly demonstrated some restrictions in using them in such composed material like fruit flesh. To determine contact surface in biological materials, a crucial analysis should include a behavior of tested fruit under external force. Herold et al. (2001) used a system consisting of a sensor in the form of a thin base die as well as the Tekscan ${ }^{\circledR}$ device, for measuring the contact surface.

As a result, they obtained distribution of surface pressure and examined apple 'Jonca' cultivar impacted against a flat plate. Contrary to these expectations, the maximum surface pressures did not appear in the surrounding area of the central point on the contact surface, but on its edge. This phenomenon can be explained by rapid destruction of loaded apple cells in the initial phase. This conclusion by Lewis et al. (2008) improved, who claimed that the characteristic shape of the recorded image results from placement of an additional layer between the examined apple and the recording head. In this way, such a conclusion can be confirmed because the tangential force which occurs during load can significantly deform obtained results.

A slightly different method of research by Rabelo et al. (2001) was described. He determined contact surface of oranges compressed between two parallel plates. The results were compared with measurement concerning the contact surface obtained while a mechanical model was used to determine where oranges were also tested and presented as a rubber sphere. Besides the fact that the applied method was invasive, the measuring system was characterized by low resolution, which significantly affected the accuracy during contact surface determination.

Surface pressure was also determined by Herold et al. (1996), Młotek et al. (2015), Stopa et al. (2014), and Van Zeebroeck et al. (2004), who applied the Tekscan ${ }^{\circledR}$ sensors to measure static as well as dynamic loads. They proved the usefulness of this method to the precise determination of acting force on the defined contact surface area and its advantage in comparison with well-known methods including force sensors and loaded point. Interesting studies were conducted by Lu et al. (2010, 2012) who used a cling film to measure impact pressure and bruises of apples dropped from different heights and on different surfaces. The applied method and received regression models considering impacted force allowed for evaluation and prediction of apple bruise in terms of the impact loads occurring during transport. The autoregressive models in different scientific areas were used. For instance, Valipour et al. (2013) tested this model in assessment of forecast considering monthly inflow of reservoir. In addition, they described a forecast in the aspect of agricultural water management in USA (Valipour 2016a). Rezaei et al. (2016) estimated many models which describe the evapotranspiration process in some provinces of Iran. Similar models were also applied in predicting rainfall on agricultural areas taking into account 
many factors (Valipour 2016b). A modeling on the basis of autoregressive analysis was conducted during potential evapotranspiration determination including climate changes as well as extreme events in the past (Valipour et al. 2017).

Most of the previous studies considered the influence of impact loads on biological material based on traditional methods including force sensors and focused on measurement of concentrated loads, which provided poor information about the course of impact. In this study, the authors used a wellknown method to measure load of the contact surface to determine layered surface pressure distribution of tested materials. In this paper, the surface pressure includes contact surface, whereas the measurement of impacted energy was neglected because of difficulty in conducting. A development of knowledge in the aspect of the impact course and its effect on fruit bruising in critical surface pressure analysis will allow to assess a resistance to bruise.

It seems to be useful in the aspect of impact course determination and analysis of obtained results to connect information concerning the surface pressure at contact moment as well as computer image analysis showing bruises to more accurately determine bruise volume and bruise threshold. Based on these circumstances, it is possible to develop solutions which minimize destruction of biological material. For this reason, another aim of this study was to determine the impact of the bottom layer's resistance properties on the mechanical damage degree of apples exposed to impact loads during free drop. In particular, the contact issue and its effects on the basis of determined surface pressure distributions in the fruit-bottom contact point concerning different heights were considered.

\section{Materials and Methods}

\section{Materials}

Material used in the study consisted of 'Golden Delicious' apple cultivar from a Polish orchard. The fruits were purchased directly from a grower in October 2015 and stored under controlled (ULO refrigerated system) atmosphere (at $2{ }^{\circ} \mathrm{C}$, relative humidity not exceeding $95 \%$, carbon dioxide concentration up to $0.7 \%$, and oxygen $2 \%$ ). An examined material has been carefully selected in terms of geometry and mass: outside diameter measured at the widest point was $71.7 \pm 1.8 \mathrm{~mm}$, and weight range was $0.163 \pm 0.003 \mathrm{~kg}$. This study included 300 apples. Ripe apples were characterized by firmness index in the range $61.9 \pm 0.5 \mathrm{~N}$, which was measured with the use of the manual penetrometer Facchini (type FT 327). Due to the refractometrical method (hand-held refractometer Hanna Instruments RMR 200, measuring range 0$32{ }^{\circ} \mathrm{Bx}$, accuracy of $\pm 0.1^{\circ} \mathrm{Bx}$ ), an additional measurement of sugar content in the fruit extract was performed, which ranged $11.1 \pm 0.6^{\circ} \mathrm{Bx}$. Strength properties of the examined material were also measured. The uniaxial compression test was carried out on an Instron 5566 test machine for 50 flesh samples taken radially from 10 selected fruits. The diameter of the cylindrical sample as well as its height were $20 \mathrm{~mm}$. The working head moved at an impact velocity of $3 \times 10^{-5} \mathrm{~ms}^{-1}$ to the moment of total sample destruction. The obtained results of load and deformation allowed for determining Young's modulus of elasticity, which amounted approximately to $3.422 \pm 0.15 \mathrm{MPa}$.

\section{Impact Tests}

This study was conducted in the Agrophysics Laboratory of the Agricultural Engineering Institute at Wroclaw University of Environmental and Life Sciences. In the lab, the temperature was $24{ }^{\circ} \mathrm{C}$ and the relative humidity was $55 \%$. The measurements of the impact loads on apples were conducted with the use of the authors' own construction test instrument (Fig. 1). This instrument consisted of hard and steel frame, and on the bottom was a flat and heavy concrete plate, on which the tested fruit has been attached. Such a construction eliminated vibration formation when the apples hit the bumper. Directly to the bumper, a vertical support arm was attached. The support arm, with an adjustable conical clamp element which holds the tested fruit, was equipped. The free drop against four different hard plates placed on the bumper was performed. The following types of surfaces were tested: concrete; spruce wood with a thickness of $5 \mathrm{~mm}$; a fivelayered cardboard with a thickness of $5 \mathrm{~mm}$, which consisted of external, smooth, and inner-corrugated sheets; and a polyethylene foam with a thickness of $3 \mathrm{~mm}$. Due to less firmness in material structure, the corrugated cardboard has good absorbing properties. Advantages of the polyethylene foam are resistance to disruption, compression, strength, and elasticity. In the test including concrete, wood, and cardboard, the pressure sensors were placed on the top surface of the tested material, while in the polyethylene foam test, the sensors were placed on the bottom surface. Moreover, such position of the sensor on the polyethylene foam eliminated measurement errors resulting from its firmness. In this study, the ultra-thin pressure sensor 9500 High Speed produced by Tekscan ${ }^{\circledR}$ was used. This sensor consisted of small sensors evenly spaced on the matrix working surface. The sensor's surface dimensions were $71.1 \times 71.1 \mathrm{~mm}$, thickness $0.2 \mathrm{~mm}$, sensel spatial resolution $3.9 / \mathrm{cm}^{2}$, and pressure increased to $8.27 \mathrm{MPa}$ (linearity up to $\pm 3 \%$, repeatability up to $\pm 3.5 \%$, hysteresis up to $\pm 4.5 \%$ of full scale, drift per log time of up to $5 \%$ ).

A support arm of the test instrument was equipped with a ruler increasing permanently, which enabled setting the drop height precisely ( $h$ every $10 \mathrm{~mm}$ in the range of $10-150 \mathrm{~mm}$ ). To conduct this measurement in a defined range at an assumed height, a vacuum pressure air pump was applied, where a suction line to fruit placed inside of the conic handle equipped 
Fig. 1 Image showing measuring instrument: 1 static bumper plate, 2 support arm, 3 test material, 4 ultra-thin pressure sensor, 5 suction line of the pump, 6 fruit handle, 7 fruit, 8 sensor handle, 9 multi-channel splitter of the signal, 10 computer PC

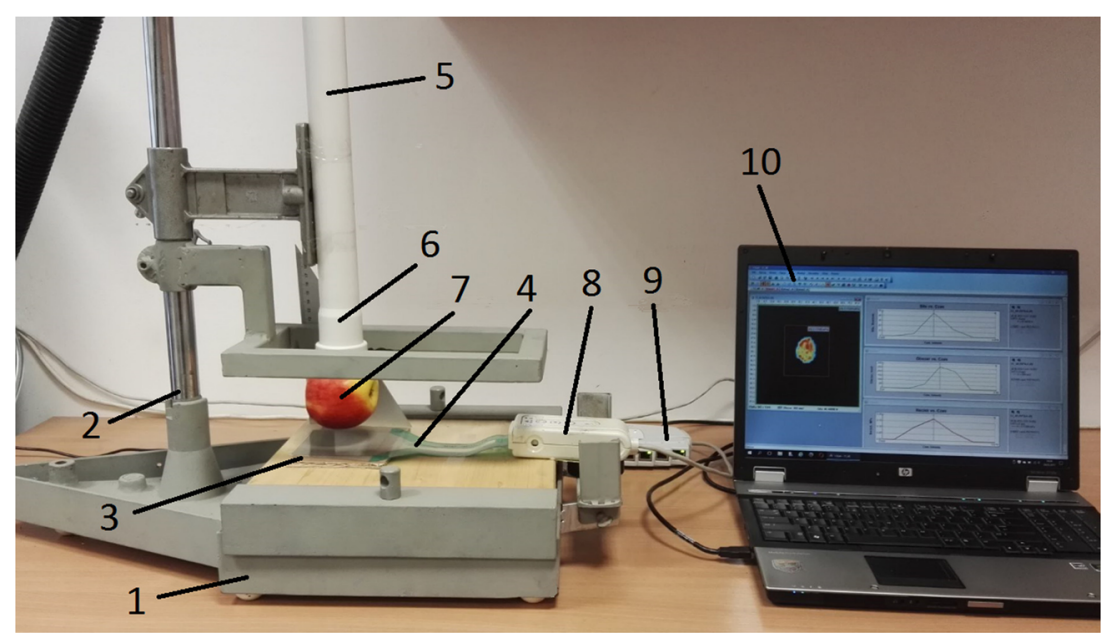

with rubber insulation was attached. The fruit was placed in a holder in lateral position. After each rebound of fruit against the fixed plate, the tested apple was stopped manually to make the next impact impossible, and the next object in the holder was placed. Measurements were conducted in a series of one impact per one fruit, 15 heights of the impact, four surfaces, and five replications. In total, this study included 300 apples. The data from the sensor to the PC by means of the multichannel thickener connected directly to a special holder were sent, in which a pressure sensor was placed. This system with the iScan program enabled data recording in real time. The sampling frequency on the whole matrix surface was $5 \mathrm{kHz}$ (VersaTek handle device). Analysis of surface pressure distribution in apples at impact moment encompassed simultaneously force impulse as well as contact area during collision against hard plate. The impact is a process on time. An analysis of images including layers recorded by the Tekscan system was considered in phase, when maximum surface pressure values occurred. As follows from a study, the force value as well as the contact surface depended significantly on maximum surface pressure at a given time.

In this study, an average value of surface pressure $p$ based on average values of impacting force $F$ which occurs on the total surface when the tested apple contacts the $A_{\mathrm{c}}$ sensor was determined. In addition, distribution of abovementioned parameters depending on drop height was analyzed. For this purpose, the measuring instrument provided a data presentation as contour distribution describing impact moment and showing maximum surface pressure $p_{\max }$ as a function of selected section $l$.

Especially, the Tekscan system generates some errors (it depends on sensor parameters, calibration, sensor resolution, sampling rate), as well as drop height (including design of measuring station), in the measurement of the bruise volume. Due to appropriate material use in test and precision during measurement repetition, error from the bruise volume findings did not exceed 5\%. Errors in research resulted from geometry of tested apples, impacted force, and contact area of apples (on contact surface, the variation in radius of curvature did not exceed 4\%). An important element improving the accuracy of the given results was focusing on condition repeatability while conducting tests (humidity, temp., measurement time). In tests, fruits of similar firmness were used. Due to a precise selection of tested objects, the shape errors as systematic errors were classified. The maximum values, obtained directly from the measuring device in the Statistica 11 software, were processed. Due to the large number of collected data and in order to improve transparency of recorded images, in this work, only selected results were presented.

\section{Bruise Area and Volume Evaluation}

After impact tests, the bruised fruits were marked and stored at room temperature for 3 days, and then a volume of the destructed apples tissue was determined. In the bruise area, the fruit peel was removed by means of knife. The measurement of the tissue deformation was carried out under daylight and with the use of a Nikon D3100 camera at air temperature of $24{ }^{\circ} \mathrm{C}$ and relative humidity of $55 \%$. The camera was placed vertically on a tripod above the tested fruit, so that the images from a fixed distance of $0.5 \mathrm{~m}$ were obtained. The surface of bruises was photographed before cutting the fruit and when the cut was along a plane passing through half a distance of the bruised surface. For computational purposes, a ruler on each image at the height of the tested fruit was placed. To determine tissue deformation in apples, computer analysis based on recorded images was conducted. For this purpose, obtained images were subjected to a color filtration procedure to emphasize the contrast of deformation using the Retinex method and the desaturation process. Pictures were processed using the raster graphics (Gimp 2.8) editing software and then presented as vector graphics. The obtained vector images were imported into AutoCAD 2016 and calibrated as well as subjected to segmentation and dimension processes to receive real 
values of the depth areas, covering the surface of bruises. The bruise volume was conducted using the "enclosed volume" method, developed by Holt and Schrool (1977). According to Kabas (2010), the determination of volume for many fruits is more accurate when the surface of the bruise is described by an elliptical shape. The bruise surface after removal of the tissue skin was calculated as surface of the ellipse described with the following formula (1).

$A_{b}=\pi w_{1} w_{2}$

where $w_{1}$ and $w_{2}$ are the larger and smaller axes of the ellipse, in millimeters.

Below, the formulas of determining the volume of bruises in the elliptical shape in accordance with the following relationships were proposed (Ahmadi et al. 2016; Blahovec and Paprštein 2005):

$V_{1}=\frac{\pi x}{24}\left(3 w_{1} w_{2}+4 x^{2}\right)$

$V_{2}=\frac{\pi y}{24}\left(3 w_{1} w_{2}+4 y^{2}\right)$

where $V_{1}, V_{2}$-volume of deformation above and below the contact surface, in cubic millimeter; $y$-bruise depth in the center and below the contact plane $(\mathrm{mm})$; and $x$-height $(\mathrm{mm})$ of the bruised apple above the contact plane (both called permanent deformation).

In our study, the radius $R$ of the apple's curvature was determined (on contact surface, the variation in the radius of the curvature did not exceed $4 \%$ ). The $R$ parameter has not been considered in formulas (2) and (3), because images that are calibrated and in contrast were transferred to the AutoCAD program where all the necessary parameters $\left(w_{1}\right.$, $\left.w_{2}, x, y\right)$ were determined by visual matching of the curve as well as the elliptical to curvature shape of the bruised area. In addition, all obtained images were maximized to the size of a full screen. To determine accuracy of edge segmentation of the bruised surface, working screen was extended and then dimensioned 10 times. In order to improve the clearness in interpretation, measured parameters are shown in Fig. 2.

Total volume $V$ of deformation was calculated as the sum of bruise volume below and above the contact surface. The above presented method allowed for visual assessment of the bruise threshold in the tested apples at various drop heights and different rigid surfaces which caused appearance of the browning points. The iScan software and computer image analysis enabled to determine the limited values of the impact heights and the average surface pressure values which resulted in the permanent deformation of tissue in 'Golden Delicious' variety. This study includes a comparison of contact surface to real bruise surface. In addition, relative bruise was calculated on the basis of the ratio between given bruise surface $A_{\mathrm{b}}$ to measured contact area $A_{\mathrm{c}}$, expressed in percentage and depending on the impact value. Analysis of relative bruise area could be implemented as a good indicator in bruise threshold determination as well as in assessing energy absorption by the tested rigid surface.

\section{Results and Discussion}

\section{Analysis of Distribution of Forces, Areas of the Contact, and Surface Pressure}

Figure $3 \mathrm{a}-\mathrm{f}$ presents the average distributions of the force impulse, the areas of contact, and the surface pressures as a function of the drop heights for the four tested hard materials. The obtained results indicated a rapid growth of the measured values during increase of the drop height, which was confirmed by high level of determination coefficients. Analysis of the obtained results showed similar changes in the force values for concrete, wood, and cardboard, where maximum values ranged from 140 to $160 \mathrm{~N}$ and the height of impact was $150 \mathrm{~mm}$ (Fig. 3a, b). For the polyethylene foam layer at each drop height, measured force values were lower by $19 \%$ in comparison to other materials, which resulted from placing the sensor under the tested material that absorbs part of energy.

The recorded results of the contact area at the impact moment confirmed this supposition. It was found that the tested polyethylene foam resulted in increase of the contact area approximately twice in comparison to other rigid surfaces (Fig. 3c, d). At the drop height of $50 \mathrm{~mm}$, the recorded contact areas for wood and concrete were similar and amounted to $240 \mathrm{~mm}^{2}$, whereas for softer cardboard, it increased to $260 \mathrm{~mm}^{2}$. The tested instrument applied in this study allowed for an identification of the significant impact of the used plates on results including contact area between the examined fruit and the sensor.

The cardboard, as well as the polyethylene foam, significantly reduced occurrence of surface pressure (Fig. 3e, f). Moreover, average surface pressure values at the drop height of $80 \mathrm{~mm}$ and placed polyethylene foam did not exceed $0.12 \mathrm{MPa}$, whereas the wood test amounted to $0.32 \mathrm{MPa}$. The highest values of surface pressure was found where concrete put for instance at the drop height of $130 \mathrm{~mm}$ was $0.41 \mathrm{MPa}$ (Fig. 3f). This can be explained by the fact that force focuses on the small contact area, and it results from mechanical properties of tested plates. For example, soft and elastic material absorbed the highest value of impact energy (polyethylene foam and cardboard) and hence can be preferred during fruit transport. The obtained results indicate that fruit impacted onto hard material (concrete) resulted in that, at the lowest drop height, the surface pressure was high and triggered a mechanical damage for the 'Golden Delicious' cultivar. 
Fig. 2 Method of bruise volume measurement

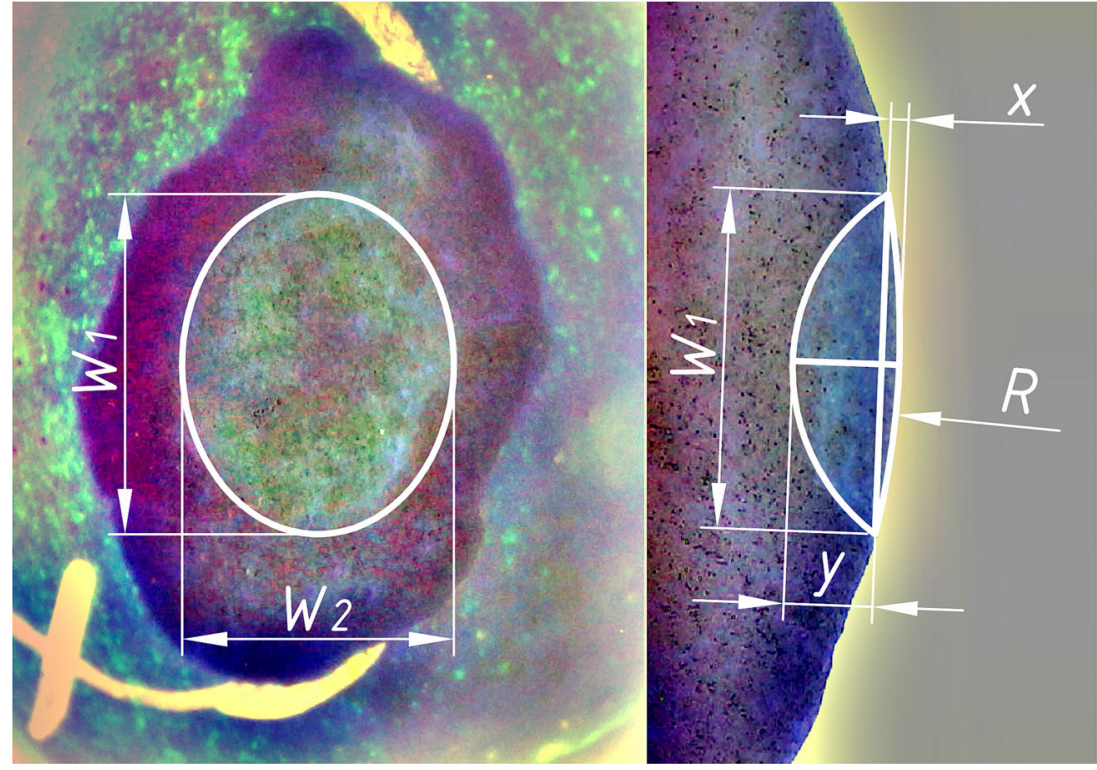

\section{Analysis of Bruise Images}

Images of bruises performed after cutting a fruit along the plane passing through half the distance of the surface covered by bruise including different materials on which fruit impacts, as well as differences in drop heights, are presented on Fig. $4 \mathrm{a}-\mathrm{d}$. This analysis shows that after 3 days of storage at room temperature, the appearance of browning bruises on the apple's surface significantly depended on the tested material and the drop height. The first symptom of bruise was observed for impact against concrete and wood while dropping the fruit from a height of $10 \mathrm{~mm}$. During impact against cardboard, changes in color on the apple's surface occurred at a drop height of $40 \mathrm{~mm}$, whereas impact onto the polyethylene foam resulted in clearly visible bruise only at drop heights above $90 \mathrm{~mm}$. The results of the descriptive statistics at a drop height of $90 \mathrm{~mm}$ are shown in Table 1.

The largest as well as most significant bruises occurred where rigid wood and concrete were tested (Fig. 4a, b), which caused slightly destructive effects in the point of impact and triggered an increase in curvature radius of bruising toward the center of the examined fruit ( $h=20$ and $50 \mathrm{~mm}$ ).

The impact of apples against a softer surface such as cardboard caused a decrease in contact area and an increase in bruise profile toward the center of the tested fruit (Fig. 4c). Photographical analysis of the apple bruise, dropped onto the polyethylene foam surface, showed an occurrence of less mechanical damages and slightly visible colors in contrast of the destroyed flesh tissue. Impact against the polyethylene foam surface in the aspect of the mechanical damage triggered a less destructive effect on the flesh tissue, because bruise was observed during impacts from $90 \mathrm{~mm}$ after external skin removal. Use of the presented method in bruise volume measurement (enclosed volume) was followed to get results similar to the Opara (2007) and Pang et al. (1992) findings. Due to the careful way of testing sample preparation and ensuring repeatability in measurement accuracy, the estimated bruise volume did not exceed 5\%. Important factors that caused errors in the evaluation of bruise volume as well as in surface bruise are method and accuracy in removing external skin from fruit, the dark and dull background of the object, lighting of the room during measurement, and fruit storage of at least $68 \mathrm{~h}$ in the same temperature conditions. Analysis of bruise images showed that use of plastic cushioning material like polyethylene foam effectively protects the fruit against impact loads. It was also noted that, at lower drop height, the development of mechanical damage under fruit peel occurred more quickly than observed on the apple surface. The abovementioned circumstances can contribute conducting future studies to research of micro-bruise occurrence and their impact on the quality of biological product under different loads.

\section{Analysis of Contours and Pressure Distributions}

The Tekscan ${ }^{\circledR}$ software enabled simultaneous recording of impulse force values and the apple contact areas on the sensor, which the authors applied in determining the contours and surface pressure distributions. The contours allowed to observe the size of real impact zones of the maximum impulse force influencing on the contact area. Figure $5 \mathrm{a}-\mathrm{f}$ shows the contour images and maximum surface pressure distributions, which depends mainly on the length section including selected drop heights and four tested materials. Computer analysis of images enabled to specify the impact heights, for which the first symptom of bruise on apples occurred. Based on this procedure, only selected contour surface pressures were presented. For instance, from the contour images at a drop height of $10 \mathrm{~mm}$ against the concrete, the zone of the maximum 
(a)

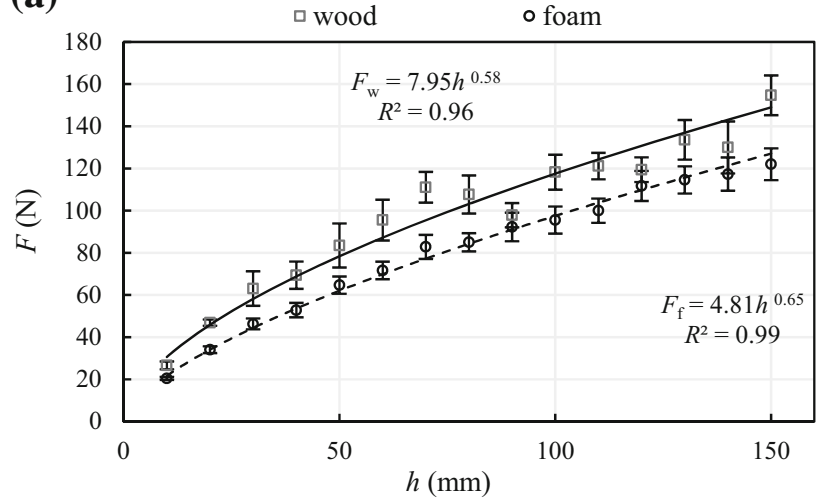

(c)

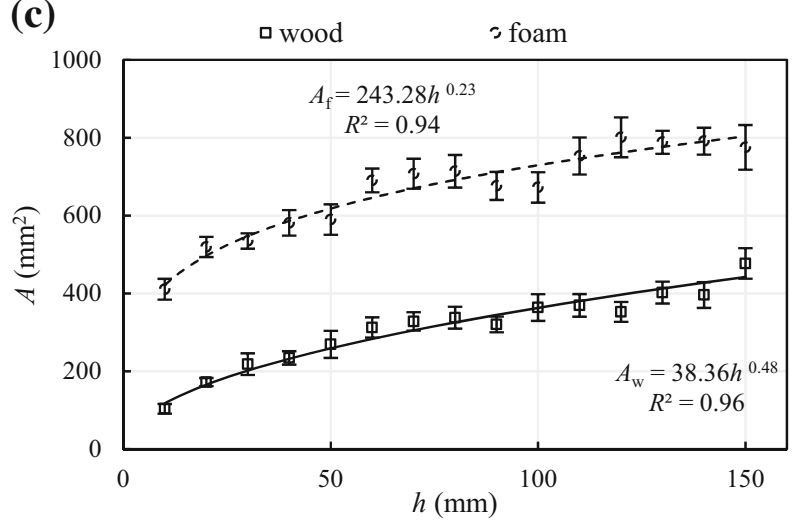

(e)

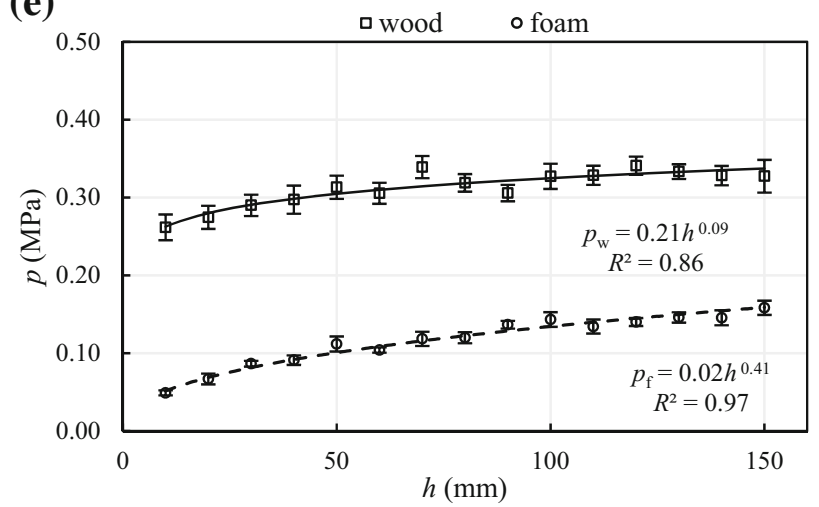

(b)

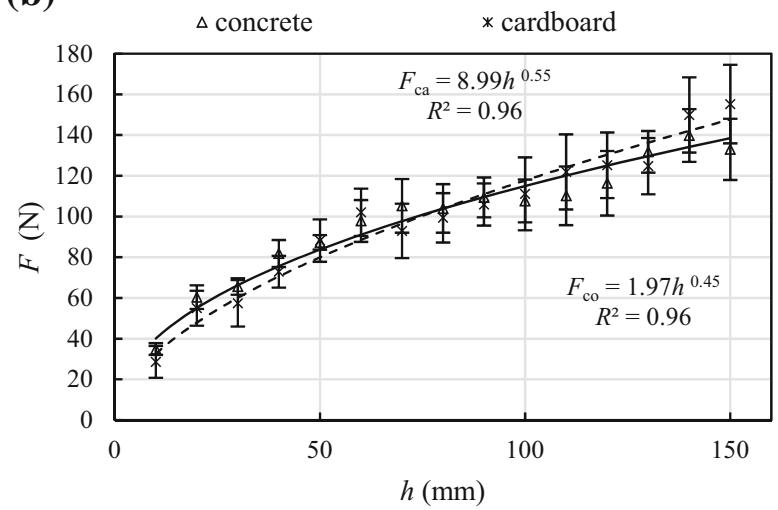

(d)

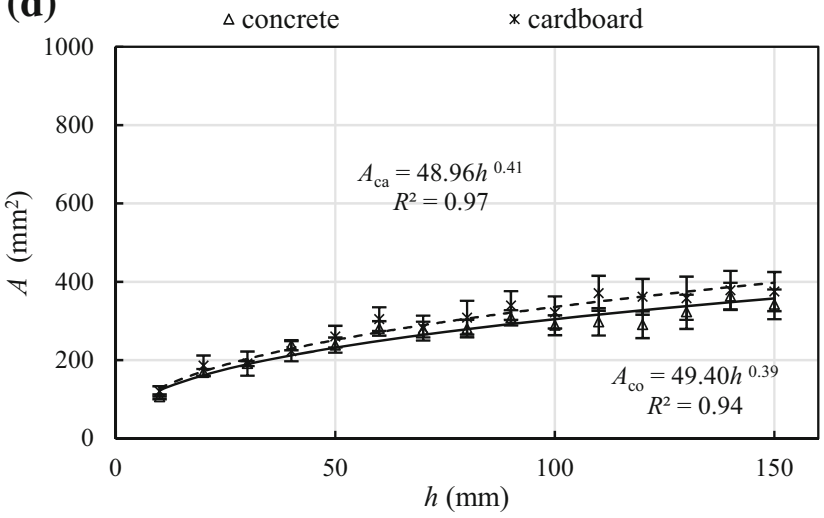

(f)

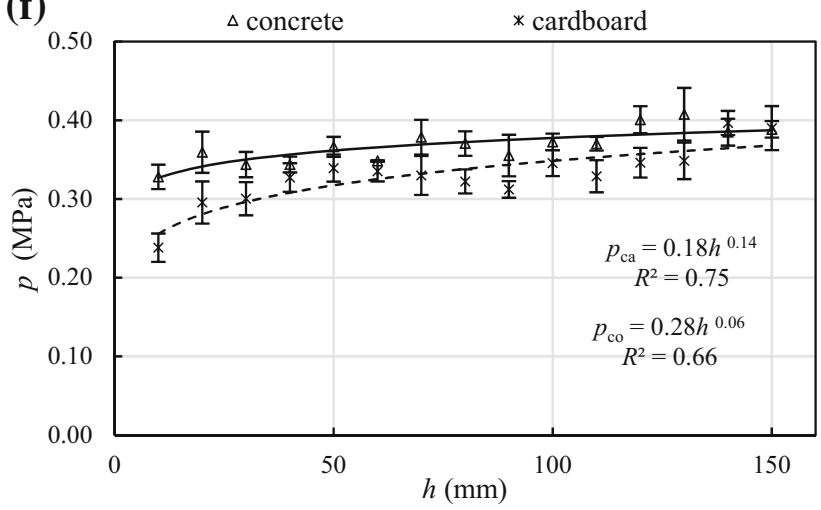

Fig. 3 Impact of the drop height on the average values. a, b Impulse of forces. c, $\mathbf{d}$ Contact areas. e, $\mathbf{f}$ The surface pressure for the four substrates: wood, polyethylene foam, concrete, and cardboard. Error bars represent mean \pm SD (standard deviation)

surface pressure occurred in the center of the contact area and amounted to $0.45 \mathrm{MPa}$ (Fig. 5a, b). A graphical analysis of images confirmed that impact from $10 \mathrm{~mm}$ height caused visible bruises. It may be assumed that for this impact, a critical value of the surface pressure was exceeded. The distribution of surface pressure at a drop height of $30 \mathrm{~mm}$ found a relocation of the maximum value $\left(p_{\max }=0.48 \mathrm{MPa}\right.$ ) toward the edges of the contact zone; at the same time, it declined in the central part of the contact area and amounted to $0.28 \mathrm{MPa}$.

Similar trend of changes in the surface pressure-length section relationship for wood material was recorded (Fig. 5d). In this case, impact from a height of $10 \mathrm{~mm}$ caused a slight flattening of the maximum surface pressure distribution in the central zone of contact up to $0.4 \mathrm{MPa}$, which indicates a degradation process in apple flesh tissue which has already started. The images of contours clearly showed that impact against rigid material such as concrete or wood generates large values of surface pressure, which causes a permanent deformation of apple flesh tissue, observed on images in the form of browning areas. Similar results were obtained by Lewis et al. (2008) while determining the surface pressure in apples compressed between two flat plates. This study was based on the 
(a) concrete
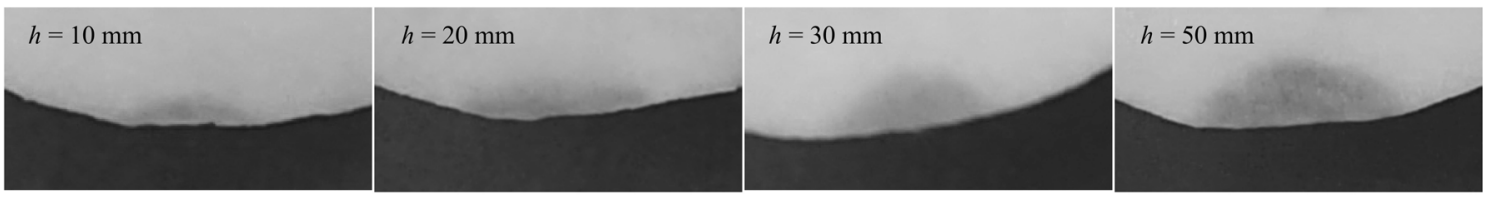

(b) wood
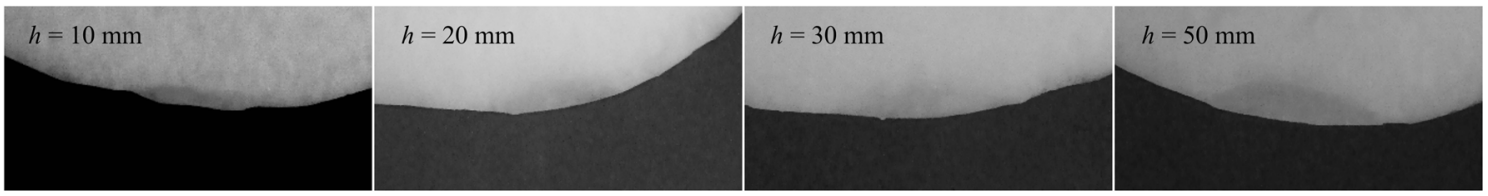

\section{(c) cardboard}

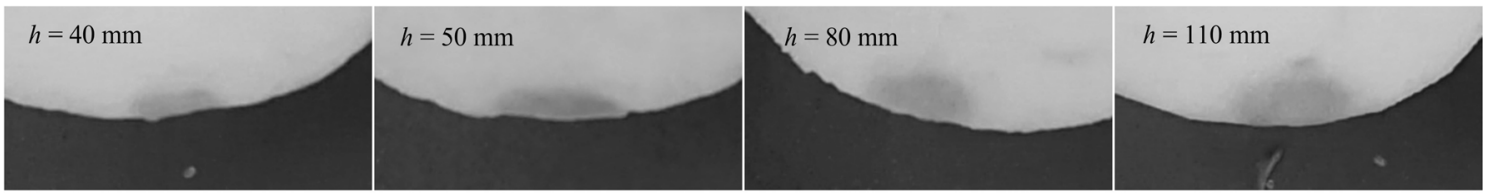

(d) foam

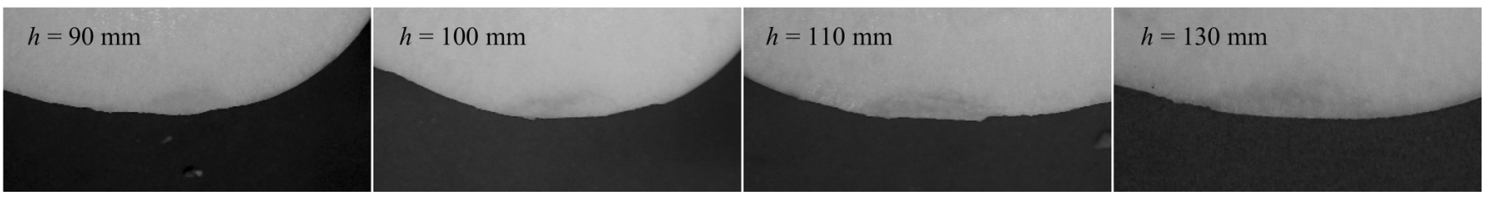

Fig. 4 Images occurred after cutting a fruit along the plane passing through the middle of the areas covered by the bruise, for selected drop heights and various type of materials. a Concrete. b Wood. c Cardboard. d Polyethylene foam

use of an ultrasonic wave (Dwyer-Joyce and Drinkwater 1998; Marshall et al. 2004). As a result, these authors obtained impact force-pressure distribution function along the contact plane. The highest surface pressure values were found in the central point of contact between the fruit and the loading device. These results varied clearly from tests obtained by Herold et al. (2001), who showed that it takes place only for one critical value, above which follows the rapid loss in cell volume located in the central point of contact, and as consequence, maximum surface pressure values on the edge of contact area were observed. It was assumed that the critical value corresponded with the point where destruction in the biological material occurs. Ahmadi et al. (2016), while measuring the collision of apples against the rigid plate and the impacts between apples, noticed that the wave of maximum stress during the impact moved from the central point of collision
Table 1 The results of the statistical analysis of tested parameters for the drop height of $90 \mathrm{~mm}$

\begin{tabular}{llrccc}
\hline Variable & Number & Mean & Standard deviation & Maximum value & Minimum value \\
\hline$F_{\text {co }}(\mathrm{N})$ & 5 & 109.40 & 9.81 & 121.21 & 98.62 \\
$F_{\mathrm{w}}(\mathrm{N})$ & 5 & 97.83 & 5.75 & 103.99 & 91.43 \\
$F_{\mathrm{ca}}(\mathrm{N})$ & 5 & 105.92 & 10.36 & 118.25 & 93.95 \\
$F_{\mathrm{f}}(\mathrm{N})$ & 5 & 92.25 & 6.78 & 101.03 & 84.80 \\
$A_{\mathrm{co}}\left(\mathrm{mm}^{3}\right)$ & 5 & 308.11 & 39.40 & 349.12 & 266.22 \\
$A_{\mathrm{w}}\left(\mathrm{mm}^{3}\right)$ & 5 & 320.40 & 20.19 & 351.04 & 293.56 \\
$A_{\mathrm{ca}}\left(\mathrm{mm}^{3}\right)$ & 5 & 339.33 & 73.65 & 414.48 & 264.18 \\
$A_{\mathrm{f}}\left(\mathrm{mm}^{3}\right)$ & 5 & 676.17 & 36.03 & 715.09 & 638.01 \\
$p_{\mathrm{co}}(\mathrm{MPa})$ & 5 & 0.355 & 0.026 & 0.392 & 0.317 \\
$p_{\mathrm{w}}(\mathrm{MPa})$ & 5 & 0.306 & 0.011 & 0.322 & 0.288 \\
$p_{\mathrm{ca}}(\mathrm{MPa})$ & 5 & 0.312 & 0.010 & 0.323 & 0.297 \\
$p_{\mathrm{f}}(\mathrm{MPa})$ & 5 & 0.137 & 0.005 & 0.153 & 0.130 \\
\hline
\end{tabular}

Marking of indexes for four substrates: concrete (co), wood (w), cardboard (ca), foam (f) 
(a) concrete, $h=10 \mathrm{~mm}$
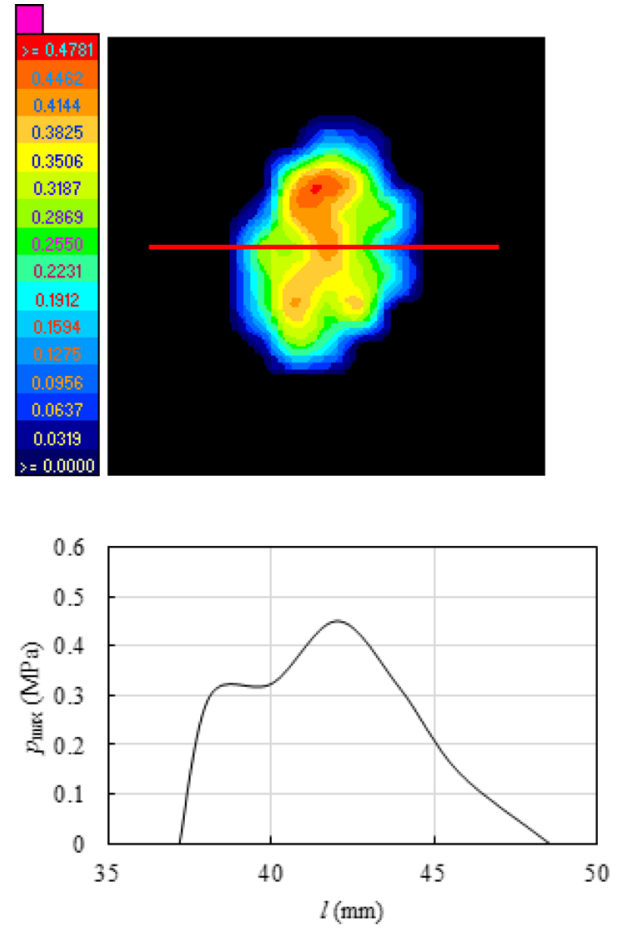

(c) wood, $h=10 \mathrm{~mm}$
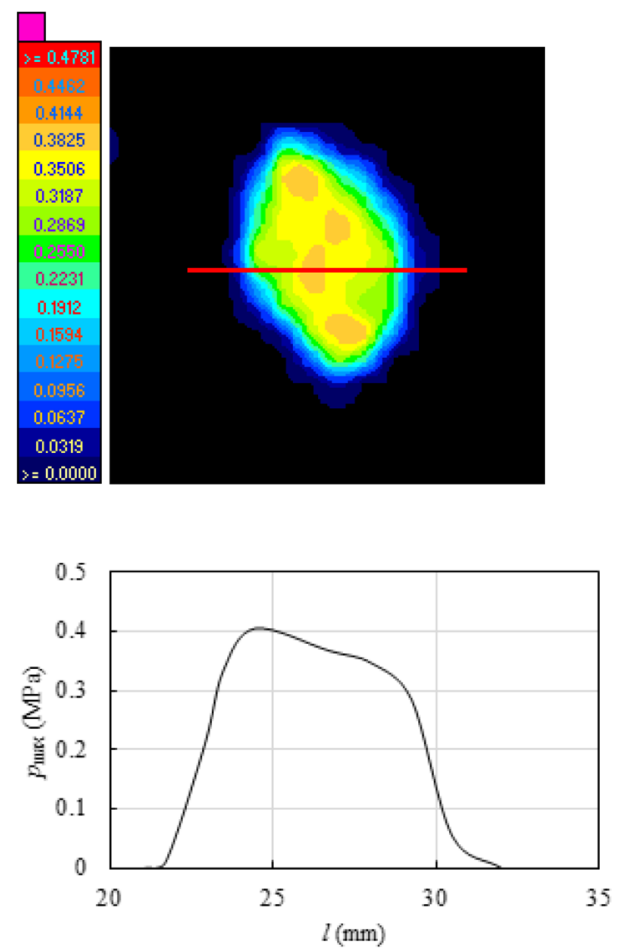

(b) concrete, $h=30 \mathrm{~mm}$
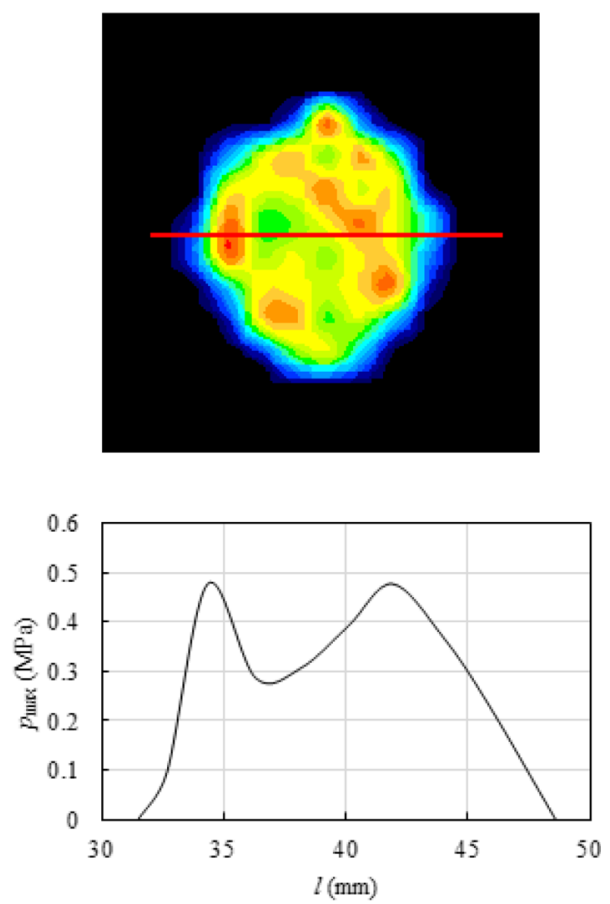

(d) wood, $h=30 \mathrm{~mm}$
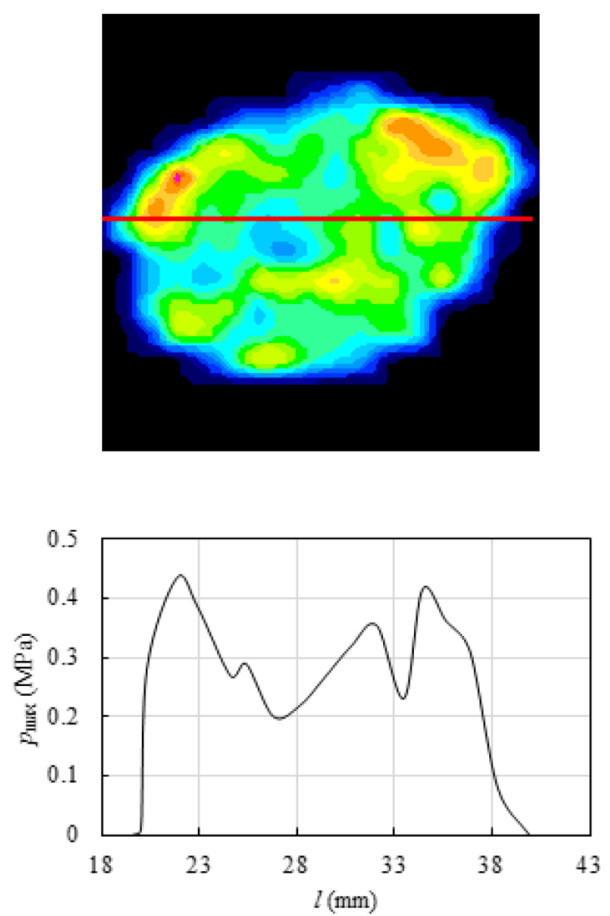

Fig. 5 Contours and surface pressures distributions for three substrate material. a, b Concrete. c, d Spruce wood. e, f Cardboard

to the boundary contact areas. Distributions of the maximum surface pressure at the moment of impact against the cardboard surface are shown in Fig. 5e, f.
Due to the specific build of the cardboard, surface pressure contours did not show a regular circular shape on the contact area. On recorded images, the parallel lines of the deformed 
(e) cardboard, $h=30 \mathrm{~mm}$
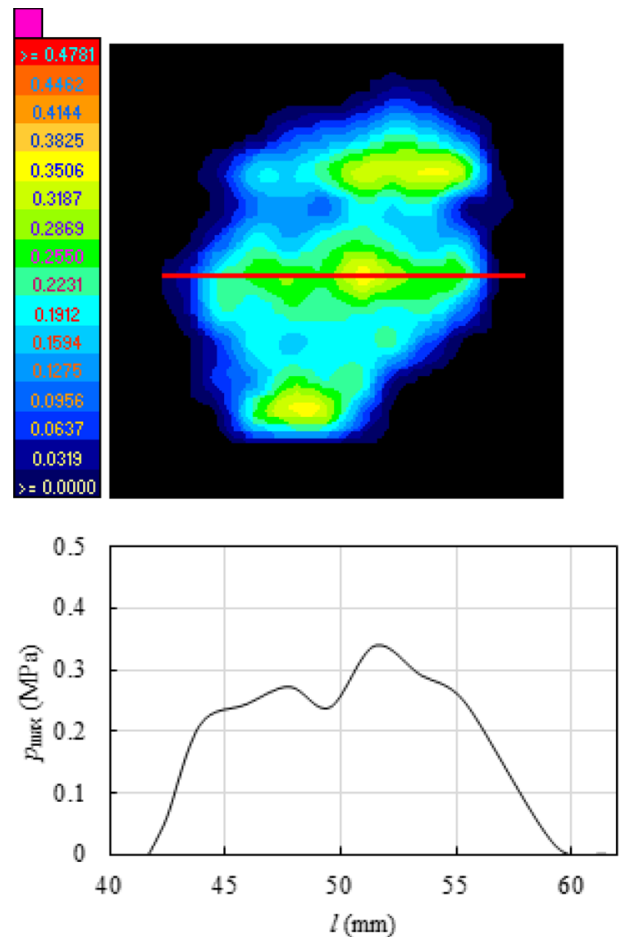

(f) cardboard, $h=50 \mathrm{~mm}$
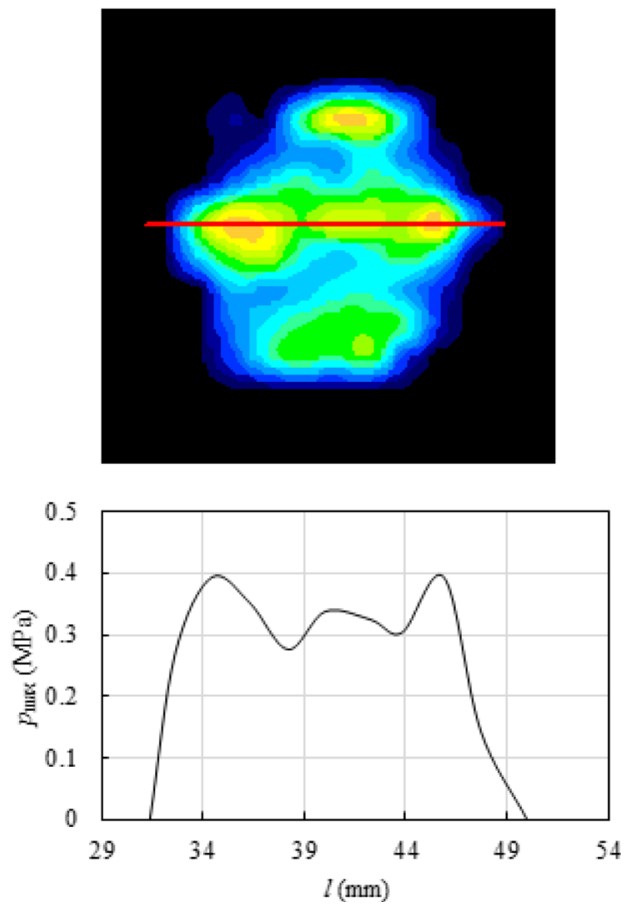

Fig. 5 (continued)

structure resulting from the material's shape were visible, for which the surface pressure values amounted locally to $0.34 \mathrm{MPa}$, while the drop height was $30 \mathrm{~mm}$. According to photographical analysis, the given height did not influence the bruise occurrence in apples. In contrast, impact from $-50 \mathrm{~mm}$ height (Fig. 5f) caused visible bruises on the apple's surface and a characteristic move of maximum surface pressure toward the boundary areas of the contact plane, which amounted to $0.39 \mathrm{MPa}$.

Fruit impact against the polyethylene foam from three defined heights 80, 90, and $110 \mathrm{~mm}$ is shown in Fig. 6a-c. It should be noted that for these drop heights, the contact area significantly increased whereas the maximum surface pressure zone decreased. Due to the fact that visible bruising on the polyethylene foam occurred at a drop height of $90 \mathrm{~mm}$ (Fig. 4d), the authors decided to present contour images before bruise occurrence (at $h=80 \mathrm{~mm}$ ) and after the appearance of bruise (at $h=110 \mathrm{~mm}$ ). From surface pressure distribution, section length relationship follows that the impact at a drop height of $80 \mathrm{~mm}$ caused a concentration of surface pressures which rose to $0.34 \mathrm{MPa}$ in the central zone of contact (Fig. 6a). Moreover, it generates an elastic deformation and did not cause visible destruction in the flesh tissue. A free drop of fruit from a height of $90 \mathrm{~mm}$ (Fig. 6b) triggered an increase in the area of maximum surface pressure as well as characteristic flattening of distribution to obtain a critical value of $0.41 \mathrm{MPa}$. Such a shape of distribution indicates an initial phase of plastic deformation in the examined flesh tissue and causes visible bruises. An increase in drop height to $110 \mathrm{~mm}$ (Fig. 6c) caused the movement of maximum pressure zones toward the edges of the contact plane. In the centered contact points, a decrease in surface pressure values was observed, which influenced destruction more quickly and did not transfer compressive load.

On the basis of the recorded images of contours and surface pressure distributions, it can be concluded that, considering drop height at which impact causes a permanent deformation, the destruction of flesh tissue started in the central point of contact. This analysis also shows that an increase in impact height caused a relocation of the maximum surface pressure zone; hence, a destruction process in the nearest located tissue in the boundary contact zone was observed, forming a ring shape located around the central point of contact.

\section{Analysis of the Bruise Volume and Bruise Prediction}

Influence of mean surface pressure and drop heights on bruise volume values for all the tested rigid plates is shown in Fig. $7 \mathrm{a}-\mathrm{d}$. The conducted tests confirmed that impact from a height of $10 \mathrm{~mm}$ resulted in bruise occurrence with volume findings similar to those obtained where fruit onto concrete as well as wood impacted and varied from 120 and $114 \mathrm{~mm}^{3}$. In some cases, the greatest volume of bruise was $1818 \mathrm{~mm}^{3}$, which was observed where the wooden material was tested at a drop height $150 \mathrm{~mm}$, as well as at impact onto the concrete at height exceeding $130 \mathrm{~mm}$ (Fig. 7a, c). 
Fig. 6 Contours and surface pressure distribution for impacts of apples on the polyethylene foam surface. a For the height of $80 \mathrm{~mm}$. b For the height of $90 \mathrm{~mm}$. c For the height of $110 \mathrm{~mm}$ (a) foam, $h=80 \mathrm{~mm}$
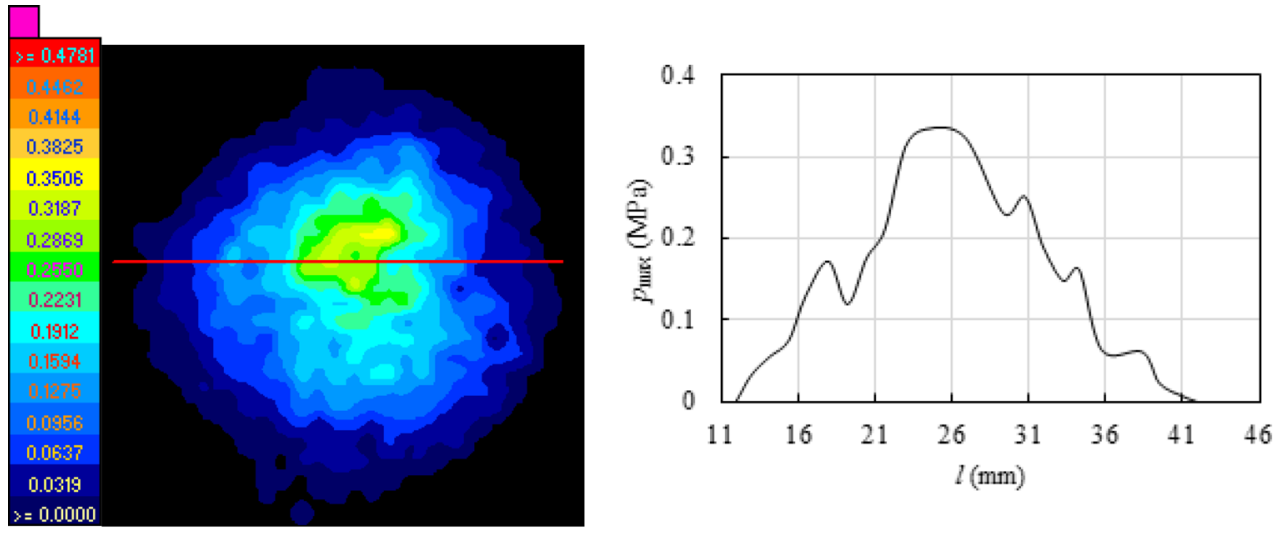

(b) foam, $h=90 \mathrm{~mm}$
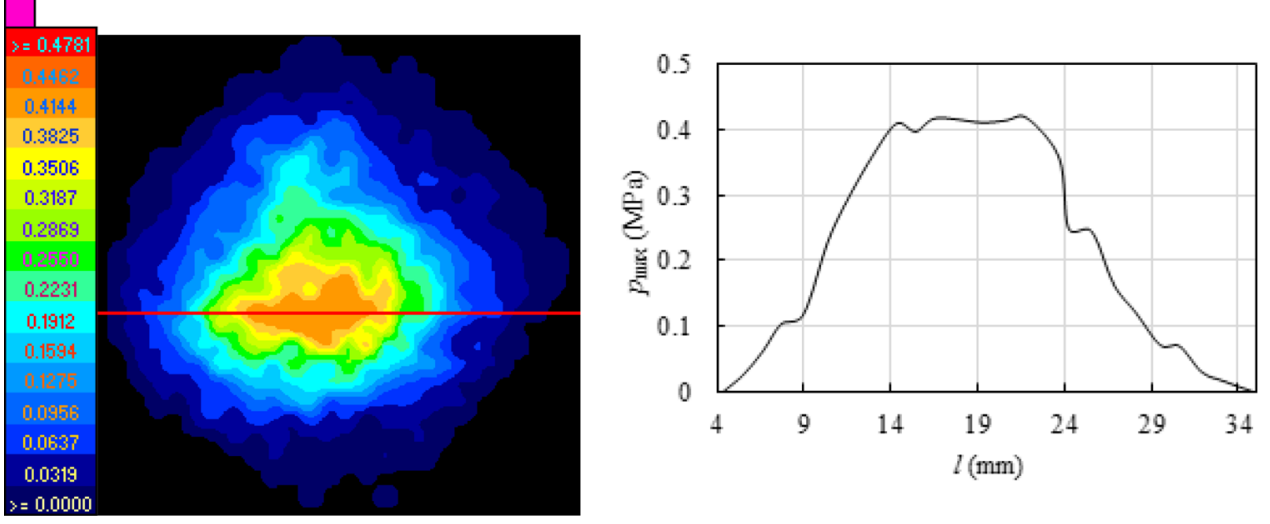

(c) foam, $h=110 \mathrm{~mm}$

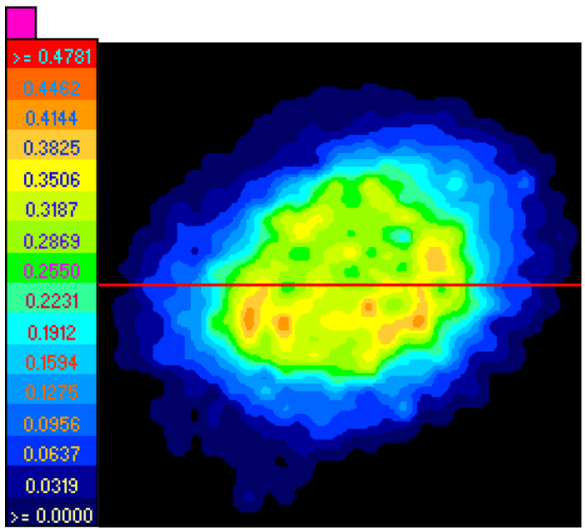

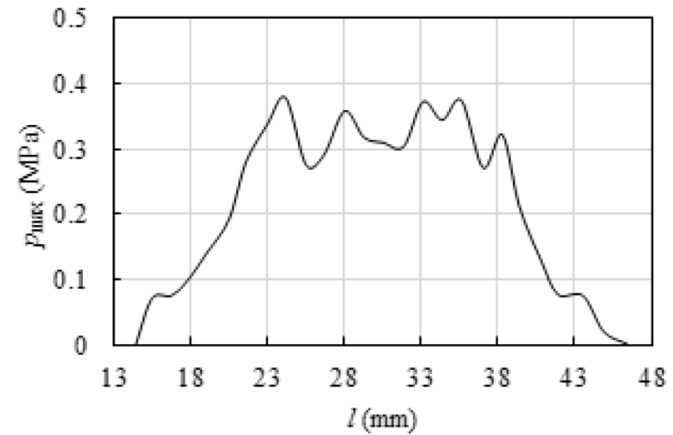

The obtained results indicate a rapid increase in the bruise volume with increasing surface pressure $(P<0.05)$. These changes are especially visible in similar ranges of surface pressure, for instance in concrete ranging from 0.32 to $0.41 \mathrm{MPa}$; for wood, from 0.26 to $0.34 \mathrm{MPa}$.

Impact of fruit against the polyethylene foam surface and cardboard surface caused a linear increase accompanied by an increase in drop height $(P<0.05)$. It was found that these surfaces reduce bruise volume up to a maximum of
$930 \mathrm{~mm}^{3}$ (Fig. 7b, d). The above presented distribution images show that more elastic surfaces cause lower bruise volume occasionally at some impact height. Fruit dropped against the cardboard surface generated a bruise volume at level $120 \mathrm{~mm}^{3}$ at height $40 \mathrm{~mm}$, whereas fruit dropped onto the polyethylene foam surface from height of $90 \mathrm{~mm}$ triggered visible bruises at level $235 \mathrm{~mm}^{3}$.

A free drop on 'Golden Delicious' variety was conducted by Chen and Yazdani (1991). They determined an impact of 
(a)

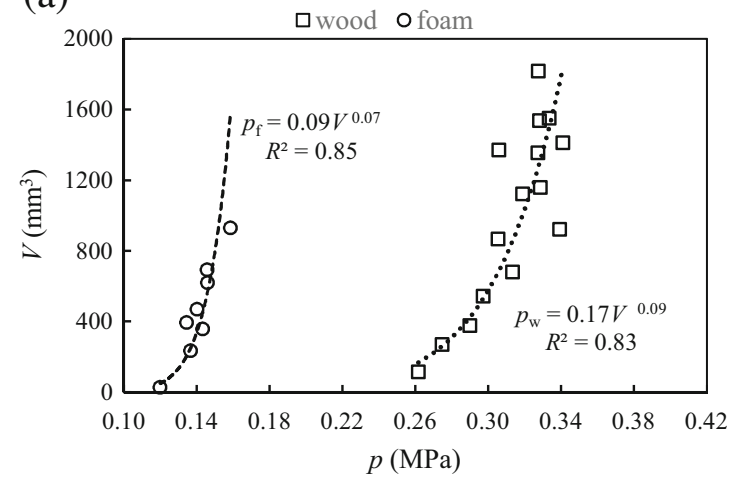

(c)

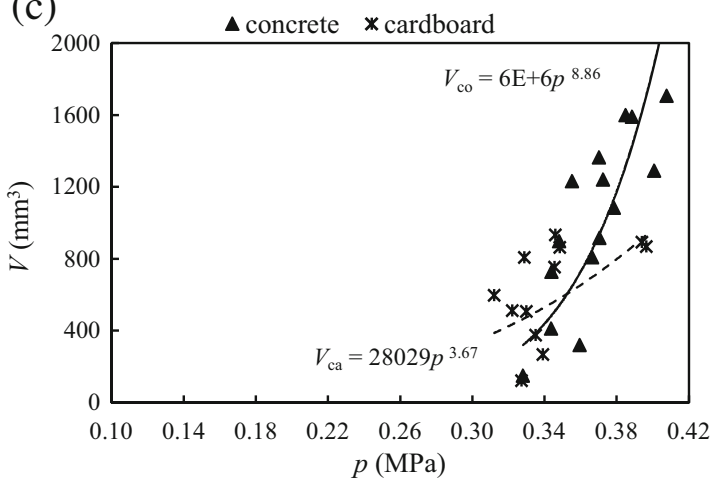

(b)

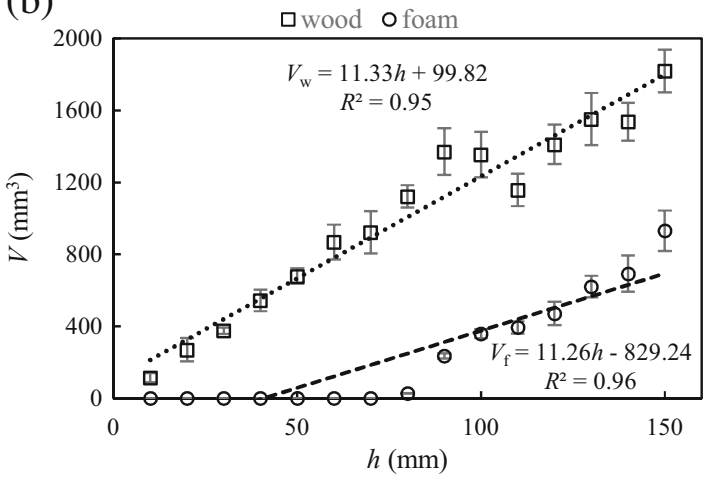

(d)

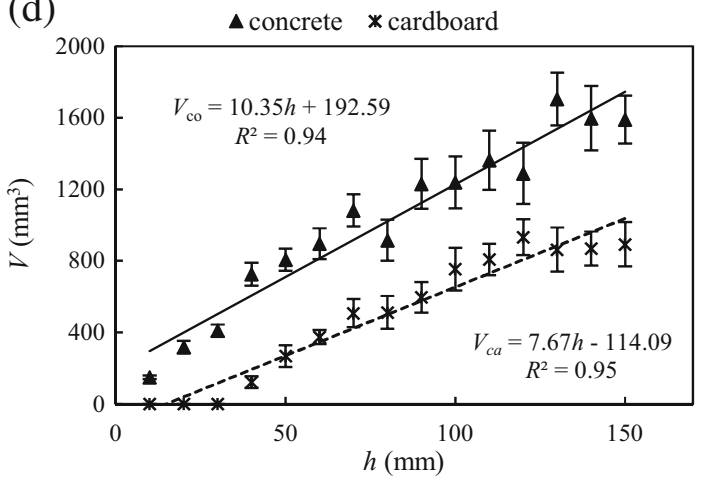

Fig. 7 Distribution of bruise volume values in relation to mean surface pressure $(\mathbf{a}, \mathbf{b})$ and the drop height $(\mathbf{c}, \mathbf{d})$ for tested substrate materials. Error bars represent mean $\pm \mathrm{SD}$ (standard deviation)

drop height and material type against which apple impacts on bruise occurrence, and as a result, they obtained similar findings to this one presented above. During the impact of apples against a fixed steel plate, they determined mean bruise volume at a level of $1700 \mathrm{~mm}^{3}$ at a drop height of $150 \mathrm{~mm}$. However, during impact test against the steel plate, on which a layer of foam (3.18 $\mathrm{mm}$ in thickness) was placed, they observed the bruise volume of $200 \mathrm{~mm}^{3}$ at a drop from $100 \mathrm{~mm}$ in height. In addition, based on the obtained results, the authors also created a linear model describing the impact of tested apples against a rigid and flat surface. From the conducted analysis of bruise, a volume-mean surface pressure relationship (Fig. 7a, c) follows a decrease in the bruise volume of fruit damage with decrease in the hardness rate of the tested materials.

Additionally, it was found that hard materials (concrete, wood) generated larger bruise volumes as well as surface pressure, whereas softer and more elastic surface plates (cardboard, polyethylene foam) significantly minimized them.

The conducted regression analysis which considered the bruise volume-impact height dependence allowed to determine and estimate models of bruise volume for each tested material (Fig. 8a-d).

The most satisfying relationship between models and experimental results was obtained for impacted fruits against the polyethylene foam and wood. The calculated estimation error for the polyethylene foam was $6.2 \%$ at a high value of determination coefficient $R^{2}=0.96$, and for the wooden material, this error was $6.5 \%$ and $R^{2}=0.97$. A slightly lower degree of matching was obtained for drops onto the cardboard surface (estimation error was $12 \%, R^{2}=0.87$ ), which resulted mainly from its corrugated shape and structure and larger volatility of obtained results (Fig. 8d). All the determined models are characterized by a linear relationship confirmed by high correlation coefficients which exceeded 0.95 for the concrete, wood, and foam, whereas that for the cardboard amounted to 0.92 .

\section{Analysis of the Relative Bruise Surface}

The last phase of this study was to compare the measured bruise surface with obtained contact area values recorded by the Tekscan device, expressed as a function of impact load depending on the tested material (Fig. 9a, b). The ratio of bruise surface $A_{\mathrm{b}}$ to the contact area $A_{\mathrm{c}}$ was presented as the relative bruise surface, expressed as percentage and compared with a reference level of $100 \%$. From comparison of relative bruise area distribution and different placed material, results that increase in drop height are accompanied by decrease in percentage of contact surface amount and higher bruise surface. Increase in drop height (to $100 \mathrm{~mm}$ ) causes higher 

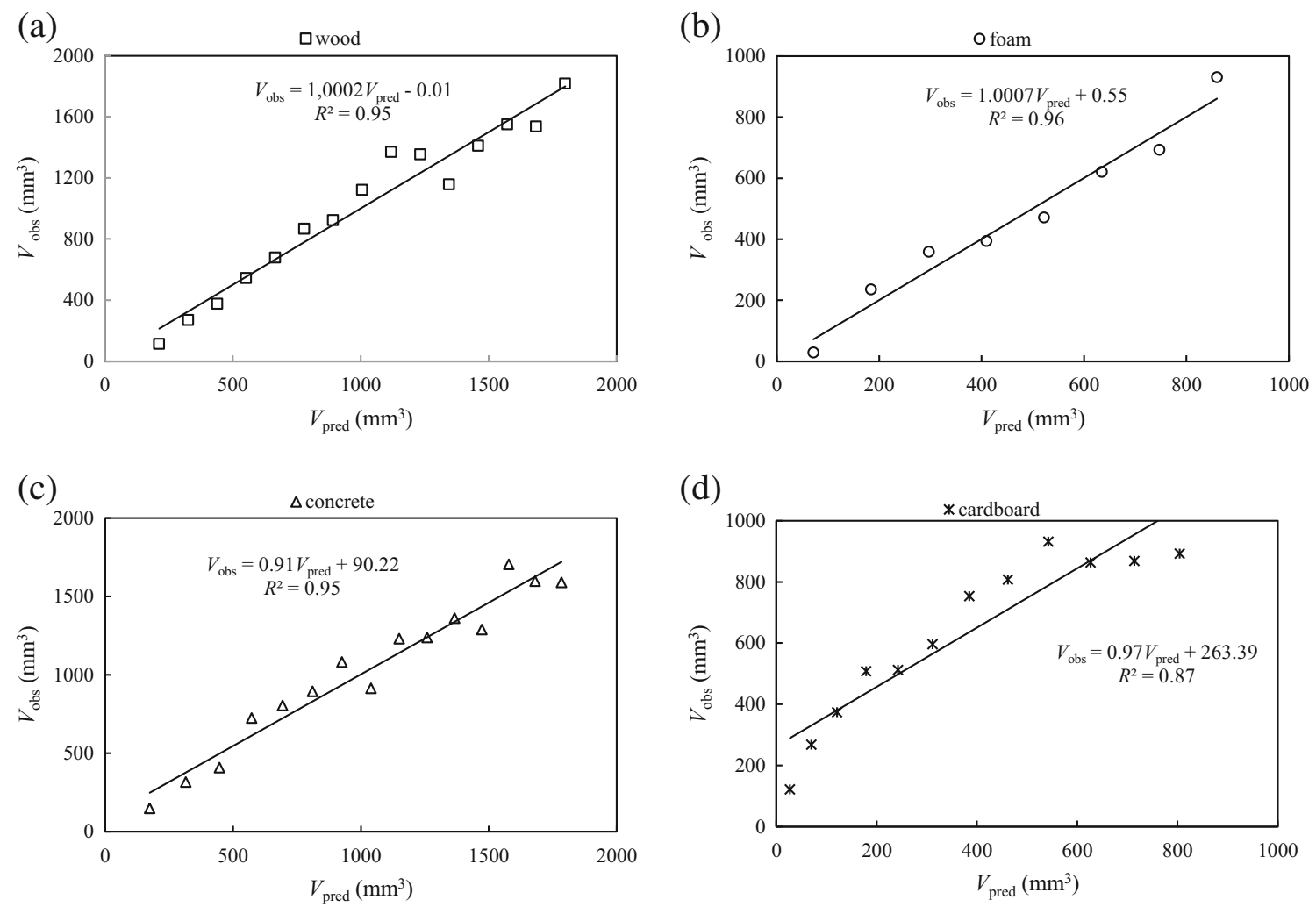

Fig. 8 The dispersion of bruise volume in comparison to the estimated model values, for tested substrates

average values of relative bruise area to maximum values and generates a constant phase which confirms drops against wood, concrete, or cardboard.

The obtained results indicate that the distributions of relative bruise areas increased, so that it was correctly described with the polynomials of $2^{\circ}$. The lowest ratio of bruise surface to the contact area was determined for impacts against the polyethylene foam and amounted to $35 \%$ at the drop height of $150 \mathrm{~mm}$. The results were confirmed by the images of pressure contours (Fig. 6ac) which presented small areas of the maximum surface pressures zones compared with the total contact area between the fruit and the recording sensor. On the basis of the relative bruise area for dropped fruit on the cardboard, it can be seen that this material absorbs part of the impact energy, because the maximum values did not exceed $87 \%$ at the drop height of $130 \mathrm{~mm}$ (Fig. 9b). Herold et al. (2001) conducted compression tests of apples using rigid surface and described differences in the contact area and the bruise area. One of the most important conclusions was the fact that the real bruise surface was about $25 \%$ lower than the contact area between the apple and the loading element. Due to another type of these studies, impact tests were conducted with the use of rigid concrete (a)

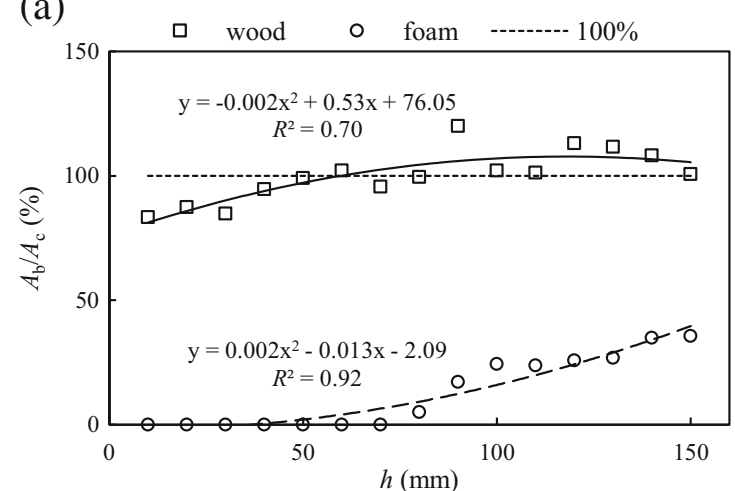

(b)

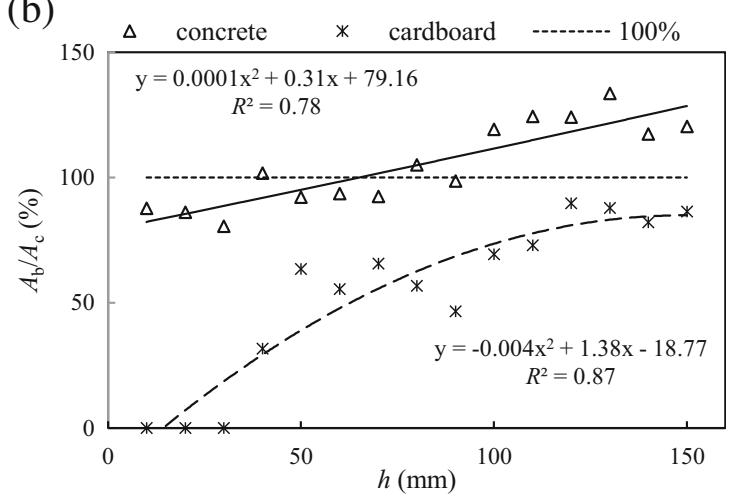

Fig. 9 The comparison of the measured bruise surface with recorded contact areas as a function of the impact height for wood and polyethylene foam (a), concrete, and cardboard (b) 
and wood, and showed that at the first drop height of $10 \mathrm{~mm}$, the bruise area constituted about $85 \%$ of the contact surface. In both cases, the relative bruise areas exceeded by $100 \%$ the bruise threshold at drop heights of $60-70 \mathrm{~mm}$. The tested concrete indicated a gradual increase in the relative bruise area up to $130 \%$ at an impact height of $130 \mathrm{~mm}$. Moreover, this state followed a destructive impact consequence, which caused an increase in the bruise area beyond the recorded contact zone. The contour images confirmed that in terms of the concrete, as well as wood, the maximum surface pressures were concentrated on the external contact zones (Fig. 5b, d). The observed phenomenon seems to be very interesting, and confirms that this permanent plastic deformation in the flesh tissue surrounds areas where the critical values of surface pressures were exceeded.

\section{Conclusions}

Impact tests for 'Golden Delicious' apple variety against various materials showed that a collision against the rigid surfaces (concrete, wood) at a drop height of $10 \mathrm{~mm}$ generated high values of surface pressure, which causes destructive changes in flesh tissue. The materials characterized by less strong properties made of the polyethylene foam triggered an increase in contact area and decrease in the surface pressures.

This analysis showed that an increase in surface pressure values is accompanied with increase in drop height, and independently of resistance surface, and leads asymptotically to the maximum values confirmed by a high value of determination coefficient $R^{2}$.

'Golden Delicious' cultivar should not be dropped against the rigid surface but also from a less height. During the fruit drop against a more elastic material, the bruise threshold should be determined, above which bruise occurs.

Computer analysis of the recorded images showed that impact of 'Golden Delicious' apple against the polyethylene foam was absorbed, because this structure causes bruise occurrence scarcely above $90 \mathrm{~mm}$ height.

The polyethylene foam, applied to this study, constituted quite good fruit protection material against mechanical damages, confirmed by the distributions of bruise area and ratio to contact area, which did not exceed $35 \%$ at the drop height of $150 \mathrm{~mm}$.

Development of micro-damages under fruit peel layer occurs more rapidly at lower drop heights and is not visible on the external surface of the apple.

Impact of the fruit on the cardboard material showed that local zones of maximum surface pressures resulted from the corrugated structure of such material and confirmed that bruise occurs from a height of $40 \mathrm{~mm}$.
Additionally, an analysis of recorded contour images and surface pressure distributions for tested contact planes (Figs. 5 and 6) allows to indicate drop height, at which the biological material used to be damaged. Independently of the material type, the permanent damage of flesh tissue in apples started in the central point of the contact surface. An increase in impact energy causes damages of flesh tissue; therefore, this part does not participate in load transfer. A larger part of impacting load is transferred by the area located on the edge of the contact zone.

The relative bruise area at the level of $130 \%$ for impact onto concrete or wooden surface indicated a distinct symptom of permanent deformation in flesh tissue surrounding maximum surface pressure zones, on which critical values were probably exceeded.

Based on these results, it can be concluded that under impact load, an increase in the firmness on the contact surface is accompanied by an increase in bruise area at similar drop heights. Therefore, a properly selected material is important in aspect of minimizing bruises during post-harvest processes.

Acknowledgements This work was supported financially by Wrocław University of Environmental and Life Sciences. The authors kindly acknowledge PPHU Sady-Trzebnica Sp. z o.o. for their support and cooperation.

Open Access This article is distributed under the terms of the Creative Commons Attribution 4.0 International License (http:// creativecommons.org/licenses/by/4.0/), which permits unrestricted use, distribution, and reproduction in any medium, provided you give appropriate credit to the original author(s) and the source, provide a link to the Creative Commons license, and indicate if changes were made.

\section{References}

Acıcan, T., Alibaș, K., \& Özelkök, I. S. (2007). Mechanical damage to apples during transport in wooden crates. Biosystems Engineering, 96(2), 239-248.

Ahmadi, E., Barikloo, H., \& Kashfi, M. (2016). Viscoelastic finite element analysis of the dynamic behavior of apple under impact loading with regard to its different layers. Computers and Electronics in Agriculture, 121, 1-11.

Blahovec, J., \& Paprštein, F. (2005). Susceptibility of pear varieties to bruising. Postharvest Biology and Technology, 38(3), 231-238.

Caleb, O. J., Opara, U. L., \& Witthuhn, C. R. (2011). Modified atmosphere packaging of pomegranate fruit and arils: a review. Food and Bioprocess Technology, 5(1), 15-30. doi:10.1007/s11947-0110525-7.

Chen, P., \& Yazdani, R. (1991). Predition of apple bruising due to impact on different surfaces. Transaction of the ASAE, 34(3), 956-961.

Costa, C., Antonucci, F., Pallottino, F., Aguzzi, J., Sun, D.-W., \& Menesatti, P. (2011). Shape analysis of agricultural products: a review of recent research advances and potential application to computer vision. Food and Bioprocess Technology, 4(5), 673-692.

Cubero, S., Aleixos, N., Moltó, E., Gómez-Sanchis, J., \& Blasco, J. (2011). Advances in machine vision applications for automatic inspection and quality evaluation of fruits and vegetables. Food and Bioprocess Technology, 4(4), 487-504. 
Delele, M. A., Ngcobo, M. E. K., Opara, U. L., \& Meyer, C. J. (2013). Investigating the effects of table grape package components and stacking on airflow, heat and mass transfer using 3-D CFD modelling. Food Bioprocess Technology, 6(9), 2571-2585. doi:10.1007/ s11947-012-0895-5.

Doosti-Irani, O., Golzarian, M. R., Aghkhani, M. H., Sadrnia, H., \& Doosti-Irani, M. (2016). Development of multiple regression model to estimate the apple's bruise depth using thermal maps. Postharvest Biology and Technology, 116, 75-79.

Dwyer-Joyce, R. S., \& Drinkwater, B. W. (1998). Analysis of contact pressure using ultrasonic reflection. Proceedings of 11th Annual Conference on Experimental Mechanics, Balkema, Rotterdam $747-754$

ElMasry, G., Kamruzzaman, M., Sun, D. W., \& Allen, P. (2012). Principles and applications of hyperspectral imaging in quality evaluation of agro-food products. A review. Critical Reviews in Food Science and Nutrition, 52(11), 999-1023.

Fadiji, T., Coetzee, C., Pathare, P., \& Opara, U. L. (2016a). Susceptibility to impact damage of apples inside ventilated corrugated paperboard packages: effects of package design. Postharvest Biology and Technology, 111, 286-296.

Fadiji, T., Coetzee, C., Chen, L., Chukwu, O., \& Opara, U. L. (2016b). Susceptibility of apples to bruising inside ventilated corrugated paperboard packages during simulated transport damage. Postharvest Biology and Technology, 118, 111-119.

Herold, B., Truppel, I., Siering, G., \& Geyer, M. (1996). A pressure measuring sphere for monitoring handling of fruit and vegetables. Computers and Electronics in Agriculture, 15, 73-88.

Herold, B., Geyer, M., \& Studman, C. J. (2001). Fruit contact pressure distributions-equipment. Computers and Electronics in Agriculture, 32, 167-179.

Holt, J. E., \& Schoorl, D. (1984). Package protection and energy dissipation in apple packs. Scientia Horticulturae, 24(2), 165-176.

Holt, J. K., \& Schrool, D. (1977). Bruising and energy dissipation in apples. Journal of Texture Studies, 7, 421-432.

Hung, Y., \& Prussia, S. (1989). Effect of maturity and storage time on the bruise susceptibility of peaches (cv. Red Globe). Transactions of the ASAE, 32(4), 1368-1373. doi:10.13031/2013.31159.

Jones, C. S., Holt, J. E., \& Schoorl, D. (1991). A model to predict damage to horticultural produce during transport. Journal of Agricultural Engineering Research, 4, 259-272.

Kabas, O. (2010). Methods of measuring bruise volume of pear (Pyrus communis L.) Journal International Journal of Food Properties, 13(5), 1178-1186.

Kheiralipour, K., Ahmadi, H., Rajabipour, A., Rafiee, S., Javan-Nikkhah, M., \& Jayas, D. S. (2013). Development of a new threshold based classification model for analyzing thermal imaging data to detect fungal infection of pistachio kernel. Agricultural Research, 2(2), $127-131$.

Komarnicki, P., Stopa, R., Szyjewicz, D., \& Młotek, M. (2016). Evaluation of bruise resistance of pears to impact load. Postharvest Biology and Technology, 114, 36-44.

Lewis, R., Yoxall, A., Marshall, M. B., \& Canty, L. A. (2008). Characterising pressure and bruising in apple fruit. Department of Mechanical Engineering, the University of Sheffield, Mappin Street, Sheffield S1 3JD, United Kingdom. Wear, 264, 37-46.

Li, Z., \& Colin, T. (2014). Quantitative evaluation of mechanical damage to fresh fruits. Trends in Food Science \& Technology, 35(2), 138 150. doi:10.1016/j.tifs.2013.12.001.

Li, J., Karkee, M., Zhang, Q., Xiao, K., \& Feng, T. (2016). Characterizing apple picking patterns for robotic harvesting. Computers and Electronics in Agriculture, 127, 633-640.

Lu, F., Ishikawa, Y., Kitazawa, H., \& Satake, T. (2010). Measurement of impact pressure and bruising of apple fruit using pressure-sensitive film technique. Journal of Food Engineering, 96(4), 614-620.
Lu, F., Ishikawa, Y., Kitazawa, H., \& Satake, T. (2012). Assessment and prediction of repetitive impact damage to apple fruit using pressuresensitive film technique. Journal: Food, Agriculture and Environment, 10(2), 156-160.

Marshall, M. B., Lewis, R., Drinkwater, B. W., \& Dwyer-Joyce, R. S. (2004). An ultrasonic approach for contact stress mapping in joints and concentrated contacts. Journal of Strain Analysis for Engineering Design, 39(4), 339-350.

Menesatti, P., Zanella, A., D’Andrea, S., Costa, C., Paglia, G., \& Pallottino, F. (2009). Supervised multivariate analysis of hyperspectral NIR images to evaluate the starch index of apples. Food and Bioprocess Technology, 2(3), 308-314.

Młotek, M., Stopa, R., Komarnicki, P., Szyjewicz, D., \& Kuta, Ł. (2015). Surface pressure distributions for pears at a constant value of load. Scientific Papers Series Management, Economic Engineering in Agriculture and Rural Development, 15(3), 189-194.

Mohsenin, N. N. (1986). Physical properties of plant and animial materials: structure. In: Physical characteristics and mechanical properties (1st ed.). New York: Gordon and Breach Science Publishers Inc.

Nicolaï, B. M., Beullens, K., Bobelyn, E., Peirs, A., Saeys, W., Theron, K. I., \& Lammertyn, J. (2007). Nondestructive measurement of fruit and vegetable quality by means of NIR spectroscopy: a review. Postharvest Biology and Technology, 46, 99-118.

Opara, L. U. (2007). Bruise susceptibilities of 'Gala' apples as affected by orchard management practices and harvest date. Postharvest Biology and Technology, 43, 47-54.

Opara, U. L., \& Pathare, P. B. (2014). Bruise damage measurement and analysis of fresh horticultural produce - a review. Postharvest Biology and Technology, 91, 9-24.

Pang, W., Studman, C. J., \& Ward, G. T. (1992). Bruising damage in apple-to-apple impact. Journal of Agricultural Engineering Research, 52, 229-240.

Pathare, P. B., Opara, U. L., Vigneault, C., Delele, M. A., \& Al-Said, F. A. J. (2012). Design of packaging vents for cooling fresh horticultural produce. Food and Bioprocess Technology, 5(6), 2031-2045. doi: 10.1007/s11947-012-0883-9.

Pathare, P. B., Opara, U. L., \& Al-Said, F. A. J. (2013). Colour measurement and analysis in fresh and processed foods: a review. Food and Bioprocess Technology, 6(1), 36-60. doi:10.1007/s11947-012-0867-9.

Rabelo, G. F., Fabbro, I. M., \& Linares, A. W. (2001). Contact stress area measurement of spherical fruit. ISHS Acta Horticulturae 562: III International Symposium on Sensors in Horticulture. doi:10. 17660/ActaHortic.2001.562.22.

Rezaei, M., Valipour, M., \& Valipour, M. (2016). Modelling evapotranspiration to increase the accuracy of the estimations based on the climatic parameters. Water Conservation Science and Engineering, 1, 197-207.

Rodriguez, L., Ruiz, M., \& De Felipe, M. R. (1990). Differences in the structural response of 'Granny-Smith' apples under mechanical impact and compression. Journal of Texture Studies, 21(2), 155-164.

Rohm, H., Jaros, D., \& DeHaan, M. (1997). A video-based method for determination of average stress-strain relations in uniaxial compression of selected foods. Journal of Texture Studies, 28(3), 245-255.

Saltveit, M. E. (1984). Effects of temperature on firmness and bruising of 'Starkrimson Delicious' and 'Golden Delicious' apples. Hort Science, 19, 550-551.

Schulte, N. L., Timm, E. J., Armstrong, P. R., \& Brown, G. K. (1991). Apple bruising, a problem during hand harvesting. American Society of Agricultural Engineers Paper No. 91-1021. (Mimeo Handout).

Stopa, R., Komarnicki, P., \& Młotek, M. (2014). Distribution of surface pressure of avocado fruit at impact loads. Agricultural. Engineering, 2(150), 163-174.

Timm, E. J., Brown, G. K., \& Armstrong, P. R. (1996). Apple damage in bulk bins during semi-trailer transport. Applied Engineering in Agriculture, 12(3), 367-377. 
Uchechukwu-Agua, A. D., Caleb, O. J., \& Opara, U. L. (2015). Postharvest handling and storage of fresh cassava root and products: a review. Food and Bioprocess Technology, 8(4), 729-748. doi:10. 1007/s11947-015-1478-z.

Valipour, M. (2016a). Variations of land use and irrigation for next decades under different scenarios. Brazilian Journal of Irrigation and Drainage, 1, 262-288.

Valipour, M. (2016b). How much meteorological information is necessary to achieve reliable accuracy for rainfall estimations? Agriculture, 6(4), 53.

Valipour, M., Banihabib, M. E., \& Behbahani, S. M. R. (2013). Comparison of the ARMA, ARIMA, and the autoregressive artificial neural network models in forecasting the monthly inflow of Dez dam reservoir. Journal of Hydrology, 476, 433-441.

Valipour, M., Sefidkouhi, M. A. G., \& Raeini-Sarjaz, M. (2017). Selecting the best model to estimate potential evapotranspiration with respect to climate change and magnitudes of extreme events. Agricultural Water Management, 180, 50-60.

Van Zeebroeck, M., Dintwa, E., Tijskens, E., Deli, V., Loodts, J., De Baerdemaeker, J., \& Ramon, H. (2004). Determining tangential contact force model parameters for viscoelastic materials (apples) using a rheometer. Postharvest Biology and Technology, 33, 111-125.

Wu, N., \& Pitts, M. J. (1999). Development and validation of a finite element model of an apple fruit cell. Postharvest Biology and Technology, 16, 1-8. 